\title{
Endometriosis and infertility: how and when to treat?
}

\author{
Anis Fadhlaoui, Jean Bouquet de la Jolinière and Anis Feki *
}

Service de gynécologie obstétrique, HFR Fribourg - Hôpital Cantonal, Fribourg, Switzerland

Edited by:

Issam Lebbi, Ob-Gyn and Fertility

Private Clinic, Dream Center, Tunisia

Reviewed by:

Salim Alfred Bassil, Al Arz Hospital, Lebanon

Hassan Nooman Sallam, Alexandria

University, Egypt

${ }^{*}$ Correspondence

Anis Feki, Service de gynécologie

obstétrique, HFR Fribourg - Hôpital

Cantonal, Chemin des Pensionnats

2-6, Case Postale, Fribourg 1708,

Switzerland

e-mail: anis.feki@h-fr.ch
Endometriosis is defined as the presence of endometrial-like tissue (glands or stroma) outside the uterus, which induces a chronic inflammatory reaction. Although endometriosis impairs fertility, it does not usually completely prevent conception. The question of evidence based-medicine guidelines in endometriosis-associated infertility is weak in many situations. Therefore, we will highlight in this issue where the challenges are.

Keywords: endometriosis, infertility, female, laparoscopic surgery, IVF, hormonal therapy

\section{INTRODUCTION}

Ovulatory disorders, tubal obstruction, and semen abnormalities account in nearly $75 \%$ of infertile couples. The remaining $25 \%$ of infertility is due to endometriosis (in up to $40 \%$ of the cases) or classified as unexplained (Table 1) (1).

Endometriosis is defined as the presence of endometriallike tissue (glands or stroma) outside the uterus, which induces a chronic inflammatory reaction (2). The exact prevalence of endometriosis is unknown but estimated to range from 2 to $10 \%$ in women of childbearing age. Its prevalence rises up to $50 \%$ in women with infertility (3).

In women with endometriosis, there is a reduced monthly fecundity rate $(2-10 \%)$ compared with fertile couples (15-20\%) (4). Although endometriosis impairs fertility, it does not usually completely prevent conception. The question of evidence basedmedicine guidelines in endometriosis-associated infertility is weak in many situations. Therefore, we will highlight in this issue where the challenges are.

\section{ENDOMETRIOSIS AND REPRODUCTION}

The fecundity in the control groups of women with endometriosis attempting to become pregnant naturally was approximately half that of a group with pure unexplained infertility without endometriosis (5). A large multicentric prospective study (6) showed a reduced fecundity in women with minimal endometriosis. Although there is a substantial evidence for relationship between endometriosis and infertility, a causal relationship has not been established. The mechanisms for endometriosis-related infertility are not fully understood and seem to be different in different stages of endometriosis.

\section{MILD OR MINIMAL ENDOMETRIOSIS AND INFERTILITY}

The mechanisms underlying reproductive failure are subtle and remain controversial, especially in cases where ovaries and fallopian tubes are normal. However, the following effects on reproduction could be noticed:
- A toxic effect on gametes, embryos, and impairment of tubal motility: endometriotic implants secrete pro-inflammatory cytokines (IL-1 $\beta$, IL-8, IL-6, and TNF $\alpha$ ), estradiol, and progesterone which attract macrophages, vascular endothelial growth factor (VEGF), and interleukin-8, thus creating an inflammatory state impairing fertility $(7,8)$.

- An abnormal follicular environment, high in cytokines (9).

- Increased rate of apoptosis in granulosa cells $(10,11)$.

- An enhanced ability to phagocytose sperm by peritoneal macrophages (12).

- A reduced rate of fertilization in women undergoing ART (13-17).

- An impairment of implantation rates and endometrial receptivity owing to the local inflammatory state and to an excessive production of antibodies to endometrial antigens (18).

\section{MODERATE TO SEVERE DISEASE AND REPRODUCTION}

In addition to above mentioned factors there is (19):

- An impairment of oocyte release owing to pelvic adhesions and endometriomas.

- An impairment of tubal transport.

- A blockage of sperm migration.

\section{MEDICAL VERSUS SURGICAL TREATMENT: WHAT IS THE BEST CHOICE AND WHAT COMES FIRST?}

The current debate is about whether it is necessary to medically treat, operate, and/or combine both treatments in infertile women.

\section{MEDICAL TREATMENT INDICATION IN REPRODUCTIVE MEDICINE}

In case of spontaneous conception, Hughes et al. (20) showed, through a large meta-analysis that ovarian suppression [oral contraceptive pill (OCP), GnRH agonists, Medroxyprogesterone acetate, Danazol] is not recommended for women with endometriosis and wishing to conceive, since there is no difference 
Table 1 | Frequency of diseases associated with infertility (1)

\begin{tabular}{llc}
\hline & Diseases & Percentage \\
\hline Female partner & Ovulatory disorders & $25-27$ \\
& Endometriosis & $5-15$ \\
& Pelvic adhesions & 12 \\
& Tubal occlusion & 11 \\
& Other tubal abnormalities & 11 \\
Male partner & Hyperprolactinemia & 7 \\
Unexplained & Abnormal semen analysis & 25 \\
Other & & 17
\end{tabular}

in spontaneous pregnancy or live births rates when compared to placebo or no treatment.

Since surgery may not remove microscopic disease, hormonal treatments have been used to suppress disease and to prevent recurrence. A meta-analysis comparing surgery plus hormonal treatment (GnRH agonists, Danazol, Medroxyprogesterone acetate) versus surgery plus placebo or no treatment showed no difference in pregnancy rates.

In infertile women with endometriosis, the Guideline Development Group (GDG) recommendation to clinicians is not to prescribe adjunctive hormonal treatment before surgery to improve spontaneous pregnancy rates, as suitable evidence is lacking (19). It is important to realize that clinicians should not withhold hormonal treatment for symptomatic women in the waiting period before undergoing surgery or medical assisted reproduction (19).

\section{SURGICAL TREATMENT}

Surgery's aim is to remove macroscopic endometriosis implants and restore normal pelvic anatomy. However, surgery may not be able to completely restore pelvic anatomy or to stop inflammatory process. Hence, it is important to weigh up benefits versus harm of surgical procedure. Laparoscopy is preferred to laparotomy because of advantages of minimal tissue damage, of magnification, of faster recovery, and shorter hospital stay (21).

\section{Is there a benefit of surgical treatment of stage I-II of endometriosis and successful pregnancy rate?}

Several studies demonstrated that, in infertile women with endometriosis stage I/II of the American Fertility Society/American Society for Reproductive Medicine (AFS/ASRM), clinicians should perform operative laparoscopy (excision or ablation of endometriosis lesions) including adhesiolysis, rather than performing diagnostic laparoscopy only, since there is a positive effect in regards to live birth and ongoing pregnancy at 20 weeks of amenorrhea (OR 1.64; 95\% CI 1.05-2.57) $(19,22)$.

According to ESHRE guidelines, and concerning management of women with stage I-II of endometriosis, clinicians may consider $\mathrm{CO}_{2}$ laser vaporization of endometriosis, instead of monopolar electro-coagulation, since laser vaporization is associated with higher cumulative spontaneous pregnancy rates (23).

\section{Is there a benefit of surgical treatment of stage III-IV of endometriosis and successful pregnancy rate?}

There is no randomized controlled trial or meta-analysis to assess whether surgery is positively effective or not on pregnancy rates in moderate to severe endometriosis. The lack of randomized trials or meta-analysis is not due to lack of research effort but to the unethical aspect of such studies that is to do nothing to a patient with stage III or IV endometriosis who is already under anesthesia could be ethically unacceptable.

There are many non-randomized uncontrolled studies with results varying from a postoperative pregnancy rate of 30-67\% (24). Three high quality prospective cohort-studies $(19,25)$ showed crude spontaneous pregnancy rates of $57-69 \%$ (moderate endometriosis) and 52-68\% (severe endometriosis) after laparoscopic surgery, which are much higher than the crude spontaneous pregnancy rates of 33\% (moderate) and $0 \%$ (severe) after expectant management reported in a study by Vercellini et al. (19).

There is conflicting evidence to determine whether removal of recto-vaginal lesions improves spontaneous pregnancy rates (2). Moreover, such a kind of aggressive surgery is accompanied by a high rate of complications $(26,27)$.The discrepancy in results between the different stages of the disease shows no correlation between the AFS classification and the outcomes in terms of fertility. Thus it is necessary to define a phenotypic profile of the lesions (28). The major benefit of surgery is achieved shortly after the first attempt because severe peri-ovarian adhesions will generally recur and will limit tubal pick-up of the ovum. If initial surgery does not result in pregnancy, subsequent surgical procedures are not likely to be effective for increasing fecundability.

A systematic review demonstrated a halving of pregnancy rates after re-operative surgery compared with first line surgery $(22 \%$ for repetitive surgery versus $40 \%$ after primary surgery) (29). The decision for re-operative surgery versus IVF must be made on symptoms, the presence of complex cysts requiring histological diagnosis, age, ovarian reserve, male factor infertility, and availability of skilled surgeons (24).

\section{HOW SHOULD WE BEHAVE WITH OVARIAN ENDOMETRIOMA IN CASE OF INFERTILITY?}

According to the ESHRE Guideline (19) in infertile women with ovarian endometrioma of $>3 \mathrm{~cm}$ in size, surgeons should perform excision of endometrioma capsule instead of ablative surgery that is drainage and electro-coagulation of the endometrioma wall since it increases the spontaneous postoperative pregnancy rate.

Excision of endometriomas involves the opening of the cyst (using scissors or electrosurgical or laser energy). After identifying the plane of cleavage between the cyst wall and ovarian tissue, the cyst wall is then excised or "stripped away" by applying opposite bimanual traction and counter actin with two grasping forceps. The ovarian edges could be sutured or inverted by light application of bipolar coagulation or kept as they are. Ablative surgery also involves the opening and drainage or fenestration (making a window in the wall of the cyst) of the endometrioma, followed by the destruction of the cyst wall using either electrosurgical current, cutting or coagulating current or a form of laser energy. 
A study by Donnez et al. (30) showed that a combined technique of excisional (cystectomy) and Laser ablative surgery without ovarian suture could be the best compromise for sparing ovarian reserve.

The ESHRE guideline (19) for the management of women with endometriosis, recommended that clinicians should counsel infertile women with endometrioma regarding the risks of reduced ovarian function after surgery and the possible loss of the ovary. The decision to proceed with surgery should be considered carefully if woman has had previous ovarian surgery.

\section{IS THERE ANY ASSOCIATION BETWEEN ENDOMETRIOMA AND RISK OF OVARIAN CANCER?}

The ESHRE's GDG concluded that there is no evidence that endometriosis causes cancer, though some cancers are slightly more common in women with endometriosis such as nonHodgkin's lymphoma and ovarian cancer (19). A very large study (31) showed a higher risk of histological subtypes of ovarian cancer in case of endometriosis. Self-reported endometriosis was associated with significantly increased risk of clear cell ovarian cancer (OR 3.05, 95\% CI 2.43-3.84), low-grade serous ovarian cancer [OR 2.11, 95\% CI 1.39-3.2 $(p<0.0001)$ ], and endometrial invasive ovarian cancer [OR 2.04, 95\% CI 1.67-2.48 $(p<0.0001)$ ]. Clinicians should be aware of this increased risk and future efforts should be focused on understanding the mechanisms that might lead to malignant transformation of endometriosis so as to help identify subsets of women at increased risk of ovarian cancer.

\section{DOES ENDOMETRIOSIS IMPACT ART OUTCOMES?}

Minimal or mild endometriosis alters the outcome of controlled ovarian hyperstimulation $(\mathrm{COH})$ in intra-uterine insemination (IUI) (32-38) with up to $30 \%$ reduction in pregnancy rate (Figure 1).

Two randomized controlled trials (24) supported the view that $\mathrm{COH}-\mathrm{IUI}$ is better than no treatment for endometriosis. Tummon and co-workers found that cumulative live birth rate was fivefold higher following $\mathrm{COH}-\mathrm{IUI}$. In a systematic review and meta-analysis about endometriosis and IVF, Harb et al. (39) found:

- There is $7 \%$ reduction in fertilization rate in stage $\mathrm{I} / \mathrm{II}$ endometriosis, and no difference in fertilization rate for stage

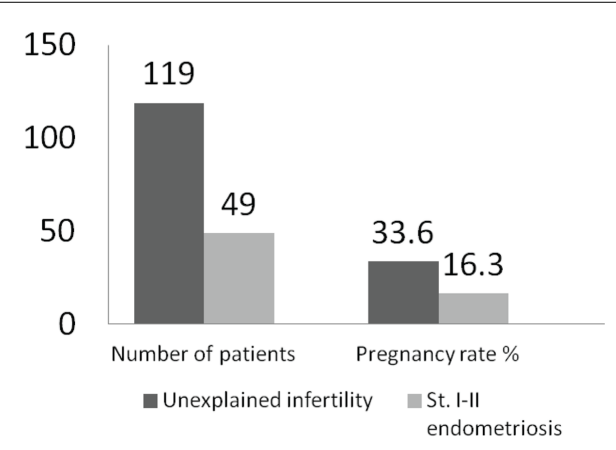

FIGURE 1 | Outcomes of COH-IUI in minimal or mild endometriosis (33).
III/IV endometriosis when compared to controls (IVF in women without endometriosis).

- There is no difference in implantation rate for stage I/II endometriosis when compared to controls, and $21 \%$ reduction in implantation rate for stage III/IV endometriosis.

- No difference in clinical pregnancies for stage I/II when compared to controls however there is $21 \%$ reduction in clinical pregnancies for stage III/IV endometriosis compared to controls.

- There is no statistical difference in live birth for all stage's endometriosis.

Concerning ovarian endometriosis, since they are dealing with all stages of endometriosis, studies show different opinions, some found no impact (40-42), and others found a decreased response but no impact on IVF outcome $(15,16,43-45)$ and finally some others found a decreased IVF outcome depending on the endometriosis severity $(19,46,47)$.

Barnhart et al., in a meta-analysis of 22 observational studies, showed that women with endometriosis have poorer IVF outcomes (the number of oocytes collected and the number of fertilized oocytes) than women with tubal infertility (OR 0.56; 95\% CI 0.4-0.7). Besides, women with more severe disease had worse outcomes than women with minimal-mild endometriosis (19).

More and more papers are reporting a reduction in ovarian reserve after laparoscopic surgery for endometriomas. Indeed, very frequently, normal ovarian tissue is excised with the endometrioma wall. Preservation of ovarian tissue (48), oocytes, or embryos cryopreservation (emergency IVF) (49) should be considered in all patients at serious risk of future fertility impairment as in case of cancers undergoing cytotoxic chemotherapies.

\section{DOES MEDICAL TREATMENT SHOULD BE BEFORE OR AFTER SURGERY IN PATIENT WITH ENDOMETRIOSIS UNDERGOING ART?}

In ART, the pre-treatment with GnRH agonists significantly increased live birth rate compared with no pre-treatment (OR 9.19; 95\% CI 1.08-78.22) (50). The very wide confidence interval around the point estimate caused some doubt on the strength of the conclusions.

A study (51) suggested that ART outcomes following OCP pretreatment in women with endometriosis are comparable with the outcomes of age-matched controls without endometriosis, thus showing a positive effect.

In one hand, in infertile women with stage I/II endometriosis, an IUI with gonadotropins controlled ovarian stimulation (COS) should be performed, instead of expectant management and instead of IUI alone as it increases respectively 5.6 and 5.1 times live birth rates. On the other hand, clinicians may consider performing IUI with COS within 6 months after surgical treatment, since pregnancy rates are similar to those achieved in unexplained in unexplained infertility (19).

However, it is less clear whether surgery for minimal - mild endometriosis prior to $\mathrm{COH}-\mathrm{IUI}$ improves the success rate (24).

The influence of endometriosis on the success rate of IVF/ICSI in not unequivocal. Barnhart et al. found that pregnancy rates after IVF/ICSI were lower in patients with stage III/IV endometriosis as compared to those with tubal factor (19). However, some 
Table 2 | Risk and benefits of observational and surgical management of endometriomas (19).

\begin{tabular}{ll}
\hline Observational & Surgery \\
\hline BENEFITS & \\
Avoid surgery & Exclude malignancy \\
Low FSH doses & Relieve symptoms \\
Increased E2 & Reduce the risk of cyst complications \\
Increased follicles & Facilitate transvaginal access to ovarian \\
& follicles
\end{tabular}

\section{RISKS}

Pain

Ovarian failure because of destruction of normal tissue

No histological diagnosis

Reduced number of egg collected

Pelvic infection following oocyte Risks of surgery retrieval

large databases (The society for assisted reproductive technologySART - and the human fertilization and embryology authority) noted that endometriosis does not adversely affect pregnancy rates. It seems that $\mathrm{GnRH}$ antagonist protocol is not inferior to $\mathrm{GnRH}$ agonist protocol in women with stage I/II endometriosis and endometrioma (19). The GDG of the ESHRE recommends the use of ART for infertility associated with endometriosis, especially if tubal function is compromised or if there is male factor infertility and/or other treatments have failed (19).

In a Cochrane review, it appears that down-regulation for 3-6 months with GnRH agonists in women with endometriosis increases the odds of clinical pregnancy by more than fourfold (50).

The benefit of surgery for endometriomas prior to IVF is still uncertain (Table 2). A number of concerns have been raised as arguments for surgery. However, the available evidence appears to alleviate these concerns:

- There is no reduced ovarian responsiveness with $\mathrm{COH}$ in women or ovaries with endometriosis (24).

- There is no risk of growth or rupture of endometriomas with $\mathrm{COH}(24)$.

- To date, there are no studies that proved an increased risk of abscess formation following oocyte retrieval in women with endometriomas (24). Clinicians may use antibiotic prophylaxis at the time of oocyte retrieval, although the risk of abscess is low (19).

- Ovarian surgery seems to reduce the number of oocytes retrieved, to reduce the peak estradiol levels and to increase total FSH requirement. It has been reported that ovarian surgery can lead to ovarian failure in $13 \%$ of the cases $(52,53)$. Beside the later, in infertile women, resection of endometriomas larger than $3 \mathrm{~cm}$ does not seem to improve pregnancy rates (19, 54-56), thus the GDG according to ESHRE guidelines recommended to consider cystectomy prior to ART to improve endometriosis-associated pain or the accessibility of follicles 22. The decision to proceed with surgery should be considered carefully if women have had previous ovarian surgery.

- Concerning deep endometriosis, there is no evidence to recommend performing surgical excision of deep nodular lesions prior to ART, to improve reproductive outcomes. However, these women often suffer from pain, requesting surgical treatment $(19,55)$.

- ART treatments do not seem to increase the recurrence rate of endometriotic lesions or symptoms (19).

\section{CONCLUSION}

Endometriosis is a common disease in infertile women. It can affect fertility in many ways and at different levels. Medical treatment of endometriosis does not improve spontaneous pregnancy rates, whereas there is evidence that surgery is beneficial in minimal-mild endometriosis. There is controversial evidence regarding removal of endometriomas owing to the potential impact on ovarian reserve, but there are benefits of this surgery such as pain relief.

Other RCT are required to assess the potential effects of aggressive surgery and re-operative procedures. ART improves pregnancy rates as compared with no treatment, but the pregnancy rates remain lower than that of endometriosis-free women. Medical, surgical, and ART treatments do not need to occur separately and many women may benefit from a combination of these three approaches.

\section{REFERENCES}

1. WB Sanders. WHO Scientific Group Report. Philadelphia, PA: WB Sanders (1999). 249 p.

2. Kennedy S, Bergqvist A, Chapron C, D’Hooghe T, Dunselman G, Greb R, et al. ESHRE guideline for the diagnosis and treatment of endometriosis. Hum Reprod (2005) 20:2698-704. doi:10.1093/humrep/dei135

3. D’Hooge T, Debrock S, Hill J, Meuleman C. Endometriosis and subfertility: is relationship resolved? Semin Reprod Med (2003) 21:243-54. doi:10.1055/s2003-41330

4. The Practice Committee of the American Society for Reproductive Medicine. Endometriosis and fertility. Fertil Steril (2004) 81:1441-6.

5. Johnson NP, Farquhar CM, Hadden WE, Suckling J, Yu Y, Sadler L. The FLUSH trial - flushing with lipiodol for unexplained (and endometriosis related) subfertility by hysterosalpingography: a randomized trial. Hum Reprod (2004) 19:2043-51. doi:10.1093/humrep/deh418

6. Berube S, Marcoux S, Langevin M. Fecundity of infertile women with minimal or mild endometriosis and women with unexplained infertility. TH Canadian collaborative group on endometriosis. Fertil Steril (1998) 69:1034-41. doi:10.1016/S0015-0282(98)00081-8

7. Shifren JL, Tseng JF, Zaloudek CJ, Ryan IP, Meng YG, Ferrara N, et al. Ovarian steroid regulation of vascular endothelial growth factor in human endometrium: implications for angiogenesis during the menstrual cycle and in the pathogenesis of endometriosis. J Clin Endocrinol Metab (1996) 81:3112-8. doi:10.1210/ jcem.81.8.8768883

8. Piva M, Horrowitz G, Sharpe-Timms KL. Interleukin-6 differentially stimulates haptoglobin production by peritoneal and endometriotic cells in vitro: a model for endometrial peritoneal interaction in endometriosis. JClin Endocrinol Metab (2001) 86:2553-61. doi:10.1210/jcem.86.6.7613

9. Carlberg M, Nejaty J, Fröysa B, Guan Y, Söder O, Bergqvist A. Elevated expression of tumour necrosis factor alpha in cultured granulosa cells from women with endometriosis. Hum Reprod (2000) 15:1250-5. doi:10.1093/humrep/15.6.1250

10. Nakahara K, Saito H, Saito T, Ito M, Ohta N, Sakai N, et al. Incidence of apoptotic bodies in membrana granulosa of the patients participating in an in vitro fertilization program. Fertil Steril (1997) 67:302-8. doi:10.1016/S0015-0282(97) 81915-2 
11. Toya M, Saito H, Ohta N, Saito T, Kaneko T, Hiroi M. Moderate and severe endometriosis is associated with alterations in the cell cycle of granulosa cells in patients undergoing in vitro fertilization and embryo transfer. Fertil Steril (2000) 73:344-50. doi:10.1016/S0015-0282(99)00507-5

12. Muscato JJ, Haney AF, Weinberg JB. Sperm phagocytosis by human peritoneal macrophages: a possible cause of infertility in endometriosis. Am J Obstet Gynecol (1982) 144:503-10.

13. Cahill DJ, Wardle PG, Maile LA, Harlow CR, Hull MG. Ovarian dysfunction in endometriosis-associated and unexplained infertility. J Assist Reprod Genet (1997) 14:554-7. doi:10.1023/A:1022568331845

14. Hull MG, Williams JA, Ray B, McLaughlin EA, Akande VA, Ford WC. The contribution of subtle oocyte or sperm dysfunction affecting fertilization in endometriosis-associated or unexplained infertility: a controlled comparison with tubal infertility and use of donor spermatozoa. Hum Reprod (1998) 13:1825-30. doi:10.1093/humrep/13.7.1825

15. Bergendal A, Naffah S, Nagy C, Bergqvist A, Sjöblom P, Hillensjö T. Outcome of IVF in patients with endometriosis in comparison with tubal factor infertility. $J$ Assist Reprod Genet (1998) 15:530-4. doi:10.1023/A:1022526002421

16. Pal L, Shifren JL, Isaacson KB, Chang Y, Leykin L, Toth TL. Impact of varying stages of endometriosis on the outcome of in vitro fertilization-embryo transfer. J Assist Reprod Genet (1998) 15:27-31. doi:10.1023/A:1022574221115

17. Norenstedt SN, Linderoth-Nagy C, Bergendal A, Sjöblom P, Bergqvist A. Reduced development potential in oocytes from women with endometriosis. J Assist Reprod Genet (2001) 18:644-9. doi:10.1023/A:1013111200251

18. Burney R, Talbi S, Hamilton A. Gene expression analysis of endometrium reveals progesterone resistance and candidate susceptibility genes in women with endometriosis. Endocrinology (2007) 148:3814-26. doi:10.1210/en.2006-1692

19. Dunselman GA, Vermeulen N, Becker C, Calhaz-Jorge C, D'Hooghe T, De Bie $\mathrm{B}$ et al. ESHRE guideline: management of women with endometriosis. Hum Reprod (2014) 29:400-12. doi:10.1093/humrep/det457

20. Hughes E, Brown J, Collins JJ, Farquhar C, Fedorkow DM, Vandekerckhove P. Ovulation suppression for endometriosis. Cochrane Database Syst Rev (2007) (3):CD000155.

21. Royal College of Obstetricians and Gynaecologists. Green-Top Guideline No. 24: Endometriosis, Investigation and Management. London: Royal College of Obstetricians and Gynaecologists (2006).

22. Marcoux S, Maheux R, Berube S. Laparoscopic surgery in infertile women with minimal or mild endometriosis. Canadian collaborative group on endometriosis. N Engl J Med (1997) 337:217-22. doi:10.1056/NEJM199707243370401

23. Chang FH, Chou HH, Soong YK, Chang MY, Lee CL, Lai YM. Efficacy of isotopic $13 \mathrm{CO}_{2}$ laser laparoscopic evaporation in the treatment of infertile patients with minimal and mild endometriosis: a life table cumulative pregnancy rates study. J Am Assoc Gynecol Laparosc (1997) 4:219-23. doi:10.1016/S1074-3804(97) 80013-8

24. Koch J, Rowan K, Rombauts L, Yazdani A, Chapman M, Johnson N. Endometriosis and fertility - a consensus statement from a ACCEPT. Aust N Z J Obstet Gynaecol (2012) 52:513-22. doi:10.1111/j.1479-828X.2012.01480.x

25. Adamson GD, Pasta DJ. Surgical treatment of endometriosis-associated infertility: meta-analysis compared with survival analysis. Am J Obstet Gynecol (1994) 171(6):1488-504. doi:10.1016/0002-9378(94)90392-1

26. Donnez J, Squifflet J. Complications, pregnancy and recurrence in a prospective series of 500 patients operated on by the shaving technique for deep endometriotic nodules. Hum Reprod (2010) 25:1949-58. doi:10.1093/humrep/deq135

27. Stepniewska A, Pomini P, Bruni F, Mereu L, Ruffo G, Ceccaroni M, et al. Laparoscopic treatment of bowel endometriosis in infertile women. Hum Reprod (2009) 24:1619-25. doi:10.1093/humrep/dep083

28. Bouquet de la Jolinière J, Feki A. "XXIst century odyssey of Medicine" stem cells and their future. Front Physiol (2013) 4:250. doi:10.3389/fphys.2013.00162

29. Vercellini P, Somigliana E, Daguati R, Barbara G, Abbiati A, Fedele L. The second time around: reproductive performance after repetitive versus primary surgery for endometriosis. Fertil Steril (2009) 92:1253-5. doi:10.1016/j.fertnstert.2009. 04.037

30. Donnez J, Lousse JC, Jadoul P, Donnez O, Squifflet J. Laparoscopic management of endometriomas using a combined technique of excisional (cystectomy) and ablative surgery. Fertil Steril (2010) 94(1):28-32. doi:10.1016/j.fertnstert.2009. 02.065

31. Pearce CL, Templeman C, Rossing MA, Lee A, Near AM, Webb PM, et al. Association between endometriosis and risk of histological subtypes of ovarian cancer: a pooled analysis of case-control studies. Lancet Oncol (2012) 13(4):385-94. doi:10.1016/S1470-2045(11)70404-1

32. Omland A, Tanbo T, Dale P, Abyholm T. Artificial insemination by husband in unexplained infertility compared with infertility associated with peritoneal endometriosis. Hum Reprod (1998) 13:2602-5. doi:10.1093/humrep/ 13.9.2602

33. Hughes E. The effectiveness of ovulation induction and intrauterine insemination in the treatment of persistent infertility: a meta-analysis. Hum Reprod (1997) 12:1865-72. doi:10.1093/humrep/12.9.1865

34. Singh M, Goldberg J, Falcone T, Nelson D, Pasqualotto E, Attaran M, et al. Superovulation and intrauterine insemination in cases of treated mild pelvic disease. J Assist Reprod Genet (2001) 18:26-9. doi:10.1023/A:1026446612485

35. Nuojua-Huttunen S, Tomas C, Bloigu R, Tuomivaara L, Martikainen H Intrauterine insemination treatment in subfertility: an analysis of factors affecting outcome. Hum Reprod (1999) 14:698-703. doi:10.1093/humrep/14. 3.698

36. Montanaro Gauci M, Kruger TF, Coetzee K, Smith K, Van Der Merwe JP, Lombard CJ. Stepwise regression analysis to study male and female factors impacting on pregnancy rate in an intrauterine insemination programme. Andrologia (2001) 33:135-41. doi:10.1046/j.1439-0272.2001.00428.x

37. Steures P, van der Steeg J, Mol B, Eijkemans MJ, van der Veen F, Habbema JD, et al. Prediction of ongoing pregnancy after intrauterine insemination. Fertil Steril (2004) 82:45-51. doi:10.1016/j.fertnstert.2003.12.028

38. Ahinko-Hakamaa K, Huhtala H, Tinkanen H. Success in intrauterine insemination: the role of etiology. Acta Obstet Gynecol Scand (2007) 86:855-60. doi:10.1080/00016340701416895

39. Harb HM, Gallos ID, Harb M, Coomarasamy A. The effect of endometriosis on in vitro fertilization outcome: a systematic review and meta-analysis. BJOG (2013) 120(11):1308-20. doi:10.1111/1471-0528.12366

40. Geber S, Paraschos T, Atkinson G, Margara R, Winston RM. Results of IVF in patients with endometriosis: the severity of the disease does not affect outcome, or the incidence of miscarriage. Hum Reprod (1995) 10(6):1507-11. doi:10.1093/HUMREP/10.6.1507

41. Olivennes F, Feldberg D, Liu HC, Cohen J, Moy F, Rosenwaks Z. Endometriosis: a stage by stage analysis - the role of in vitro fertilization. Fertil Steril (1995) 64:392-8.

42. Dmowski WP, Rana N, Michalowska J, Friberg J, Papierniak C, el-Roeiy A. The effect of endometriosis, its stage and activity, and of autoantibodies on in vitro fertilization and embryo transfer success rates. Fertil Steril (1995) 63: 555-62.

43. Al-Azemi M, Bernal AL, Steele J, Gramsbergen I, Barlow D, Kennedy S. Ovarian response to repeated controlled stimulation in in-vitro fertilization cycles in patients with ovarian endometriosis. Hum Reprod (2000) 15:73-5. doi:10.1093/humrep/15.1.72

44. dos Reis RM, Corrêa IL, Gonçalves De Angelo A, Manetta LA, de Moura $\mathrm{MD}$, Ferriani RA. In vitro fertilization in patients with ovarian endometrioma. J Assist Reprod Genet (2004) 21:311-4. doi:10.1023/B:JARG.0000043706.57616. 74

45. Suzuki T, Izumi S, Matsubayashi H, Awaji H, Yoshikata K, Makino T. Impact of ovarian endometrioma on oocytes and pregnancy outcome in in vitro fertilization. Fertil Steril (2005) 83:908-13. doi:10.1016/j.fertnstert.2004.11.028

46. Matson PL, Yovich JL. The treatment of infertility associated with endometriosis by in vitro fertilization. Fertil Steril (1986) 46:432-4.

47. Oehninger S, Acosta AA, Kreiner D, Muasher SJ, Jones HW Jr, Rosenwaks Z. In vitro fertilization and embryo transfer (IVF/ET): an established and successful therapy for endometriosis. J In vitro Fert Embryo Transf (1988) 5:249-56. doi:10.1007/BF01132172

48. Donnez J, Squifflet J, Jadoul P, Lousse JC, Dolmans MM, Donnez O. Fertility preservation in women with ovarian endometriosis. Front Biosci (Elite Ed) (2012) 4:1654-62. doi:10.2741/487

49. Elizur SE, Chian RC, Holzer HE, Gidoni Y, Tulandi T, Tan SL. Cryopreservation of oocytes in a young woman with severe and symptomatic endometriosis: a new indication for fertility preservation. Fertil Steril (2009) 91(1):293 doi:10.1016/j.fertnstert.2007.06.040

50. Sallam HN, Garcia-Velasco JA, Dias S, Arici A, Abou-Setta AM. Long-term pituitary down-regulation before in vitro fertilization (IVF) for women with endometriosis. Cochrane Database Syst Rev (2006) (1):CD004635. doi:10.1002/ 14651858.CD004635.pub2 
51. de Ziegler D, Gayet V, Aubriot FX, Fauque P, Streuli I, Wolf JP, et al. Use of oral contraceptives in women with endometriosis before assisted reproduction treatment improves outcomes. Fertil Steril (2010) 94:2796-9. doi:10.1016/j. fertnstert.2010.05.056

52. Almog B, Sheizaf B, Shalom-Paz E, Shehata F, Al-Talib A, Tulandi T. Effects of excision of ovarian endometrioma on the antral follicle count and collected oocytes for in vitro fertilization. Fertil Steril (2010) 94:2340-2. doi:10.1016/j. fertnstert.2010.01.055

53. Demirol A, Guven S, Baykal C, Gurgan T. Effect of endometrioma cystectomy on IVF outcome: a prospective randomized study. Reprod Biomed Online (2006) 12:639-43. doi:10.1016/S1472-6483(10)61192-3

54. Benschop L, Farquhar C, van der Poel N, Heineman M. Interventions for women with endometrioma prior to assisted reproductive technology. Cochrane Database Syst Rev (2010) 10:CD008571. doi:10.1002/14651858.CD008571.pub2

55. Donnez J, Wyns C, Nisolle M. Does ovarian surgery for endometriomas impair the ovarian response to gonadotropins? Fertil Steril (2001) 76:662-5. doi:10.1016/S0015-0282(01)02011-8

56. Bianchi PH, Pereira RM, Zanatta A, Alegretti JR, Motta EL, Serafini PC. Extensive excision of deep infiltrative endometriosis before in vitro fertilization significantly improves pregnancy rates. J Minim Invasive Gynecol (2009) 16:174-80. doi:10.1016/j.jmig.2008.12.009

Conflict of Interest Statement: The authors declare that the research was conducted in the absence of any commercial or financial relationships that could be construed as a potential conflict of interest.

Received: 04 March 2014; paper pending published: 14 April 2014; accepted: 15 June 2014; published online: 02 July 2014.

Citation: Fadhlaoui A, Bouquet de la Jolinière J and Feki A (2014) Endometriosis and infertility: how and when to treat? Front. Surg. 1:24. doi: 10.3389/fsurg.2014.00024

This article was submitted to Gynecology and Obstetrics, a section of the journal Frontiers in Surgery.

Copyright (c) 2014 Fadhlaoui, Bouquet de la Jolinière and Feki. This is an open-access article distributed under the terms of the Creative Commons Attribution License (CC $B Y)$. The use, distribution or reproduction in other forums is permitted, provided the original author(s) or licensor are credited and that the original publication in this journal is cited, in accordance with accepted academic practice. No use, distribution or reproduction is permitted which does not comply with these terms. 